\title{
Carbon nanotubes as catalysts for catalytic wet peroxide oxidation of highly concentrated phenol solutions: towards process intensification
}

\author{
Maria T. Pinho ${ }^{a}$, Helder T. Gomes ${ }^{\mathrm{b},}$, Rui S. Ribeiro ${ }^{\mathrm{b}}$, Joaquim L. Faria ${ }^{\mathrm{a}}$, Adrián M. T. Silva, \\ ${ }^{a}$ LCM - Laboratory of Catalysis and Materials - Associate Laboratory LSRE/LCM, Faculdade \\ de Engenharia, Universidade do Porto, Rua Dr. Roberto Frias, 4200-465 Porto, Portugal \\ ${ }^{b}$ LCM - Laboratory of Catalysis and Materials - Associate Laboratory LSRE/LCM, School of \\ Technology and Management, Polytechnic Institute of Bragança, Campus de Santa Apolónia, \\ 5300-857 Bragança, Portugal
}

*Corresponding authors e-mail addresses: E-mail addresses: adrian@fe.up.pt (A.M.T. Silva); htgomes@ipb.pt (H.T. Gomes) 


\section{Abstract}

Commercial multi-wall carbon nanotubes with different properties (2 samples from Sigma-Aldrich, SA1 and SA2; 1 sample from Nanocyl, NC; and 2 samples from Shenzhen Nanotech, SZ and LSZ) were tested as catalysts in wet peroxide oxidation. Phenol was selected as model compound since represents a class of noxious compounds for human health and for the environment and, due to this, phenol is typically considered in wastewater treatment studies. The experiments were carried out under the following intensified conditions: phenol concentration $=4.5 \mathrm{~g} \mathrm{~L}^{-1}$, hydrogen peroxide concentration $=25 \mathrm{~g} \mathrm{~L}^{-1}$, catalyst load $=2.5 \mathrm{~g} \mathrm{~L}^{-1}$, $\mathrm{pH}=3.5, \mathrm{~T}=353 \mathrm{~K}$ and $24 \mathrm{~h}$.

The results demonstrated that phenol is poorly adsorbed in this type of carbon materials (11\% as maximum when using the NC sample). However, in the catalytic experiments, complete removal of phenol is achieved when using some of the carbon nanotubes (SA1, NC and SA2), together with a remarkable total organic carbon removal (77, 69 and $67 \%$, respectively). These materials have the most pronounced basic character, which is often considered benefic for oxidation reactions in advanced oxidation processes and may explain the higher performance of SA1, NC and SA2 regarding the other materials. Leaching of Fe species into the solution was also observed in all cases, SA1 leading to the highest concentration of Fe species leached $\left(26 \mathrm{mg} \mathrm{L}^{-1}\right)$, followed by SA2 $\left(2 \mathrm{mg} \mathrm{L}^{-1}\right)$ and $\mathrm{NC}\left(1 \mathrm{mg} \mathrm{L}^{-1}\right)$.

Considering the lower Fe leaching levels observed for SA2 and NC, these catalysts were then tested in consecutive reusability cycles. SA2 showed a superior performance than NC, however, temperature programmed desorption, as well as thermogravimetric analysis, suggested that the carbon material is oxidized by hydrogen peroxide at the employed conditions and/or that carboxylic acids are adsorbed on the catalyst surface after consecutive runs (mainly after the first use), slightly reducing the catalyst activity.

Keywords: Catalytic wet peroxide oxidation; Carbon nanotubes; Phenol; Highly polluted effluents; Intensified process conditions. 


\section{Introduction}

Organic pollutants like phenol and its derivatives appear in wastewaters from pharmaceutical, paper, petrochemical and from many other industries. These compounds are very toxic and difficult to eliminate from wastewaters by conventional biological processes, in particular when they are present in high concentrations $\left(1-10 \mathrm{~g} \mathrm{~L}^{-1}\right)$ [1]. In the quest to solve this problem, different treatments have been studied based on physical and chemical processes (e.g., flocculation, precipitation, adsorption on activated carbon, ozonation, chlorination and coagulation) [2]. Advanced oxidation processes (AOPs) have been particularly investigated among the chemical treatments [3-5].

AOPs are conceptually characterized by the production of hydroxyl radicals $\left(\mathrm{HO}^{\circ}\right)$, which are very reactive species capable to oxidize a wide range of organic compounds and to reduce the toxicity of many effluents. Most of these processes can be operated at (or close to) ambient temperature and atmospheric pressure [6]. Different oxidizing agents (typically hydrogen peroxide, ozone or/and oxygen) can be considered depending on the process [7]. Particularly, hydrogen peroxide $\left(\mathrm{H}_{2} \mathrm{O}_{2}\right)$ - a colorless and non-toxic compound - is a powerful oxidizing agent that easily decomposes into environmental friendly products (i.e. water and oxygen), following Eq. (1).

$$
2 \mathrm{H}_{2} \mathrm{O}_{2} \rightarrow \mathrm{O}_{2}+2 \mathrm{H}_{2} \mathrm{O}
$$

If a suitable catalyst is used, the decomposition of $\mathrm{H}_{2} \mathrm{O}_{2}$ may proceed selectively through the formation of the highly reactive $\mathrm{HO}^{\bullet}$ radicals. This process is known as catalytic wet peroxide oxidation (CWPO). The classical Fenton process is one of the most known homogeneous AOPs, where a mixture of $\mathrm{H}_{2} \mathrm{O}_{2}$ and $\mathrm{Fe}^{2+}$ ions are employed at low $\mathrm{pH}(2.5-3.0)$ to promote the decomposition of $\mathrm{H}_{2} \mathrm{O}_{2}$ into $\mathrm{HO}^{\bullet}$ radicals, this process being considered one particular case of CWPO (i.e. a specific catalyst at specific operating conditions). Still, heterogeneous catalysts can be easier separated from the treated solution when compared to homogeneous catalysts, 
which is an important advantage relatively to the homogenous route [3]. Taking this into consideration, different supports, like activated carbons, pillared clays, zeolites, carbon xerogels and carbon nanotubes, have been employed in the last two decades to prepare transition-metal supported catalysts for CWPO [4, 8-12]. However, the loss of activity due to leaching of metal species when using heterogeneous catalysts, as well as further separation of these species from the treated water (when in quantities larger than those allowed by local Directives), are some of the arising difficulties in the use of transition-metal based catalysts. In order to overcome these drawbacks, metal-free carbon materials have been also tested as catalysts in CWPO, revealing promising activities [13-16].

Carbon nanotubes (CNT) have interesting properties when they are compared with other carbon materials, such as low mass transfer limitations, high level of ordering and mechanical resistance, superior electronic properties and relatively high thermal stability in oxidizing conditions. CNT are often produced by chemical vapour deposition (CVD) using metal nanoparticles as catalysts (such as $\mathrm{Fe}, \mathrm{Co}, \mathrm{Ni}, \mathrm{Cu}, \mathrm{Au}, \mathrm{Ag}, \mathrm{Pt}$ and $\mathrm{Pd}$ ). In this catalytic method of synthesis, a hydrocarbon gas decomposes leading to the formation and growth of CNT on the top surface of the catalytic nanoparticles [17]. It is thus natural to found metal nanoparticles in the composition of commercial CNT. These metal species (especially Fe) are able to act as catalysts in the generation of $\mathrm{HO}^{\circ}$ radicals from $\mathrm{H}_{2} \mathrm{O}_{2}$ decomposition. In accordance, this feature of the commercial CNT should be beneficial for CWPO, in addition to the recognized intrinsic catalytic activity of carbon materials, and both have to be considered when using CNT as catalysts on their own for CWPO processes.

In the present work, six different commercial CNT samples were compared as catalysts for the CWPO process. A highly concentrated phenol $\left(4.5 \mathrm{~g} \mathrm{~L}^{-1}\right)$ solution was considered as model system, in order to simulate highly polluted wastewaters and to maximize the efficiency of $\mathrm{H}_{2} \mathrm{O}_{2}$ consumption, which is known to be favoured by high phenol/carbon mass ratios [18]. Under these conditions, the carbon surface is expected to stay largely covered by the organic 
molecules, reducing the occurrence of parasitic scavenging reactions on the carbon surface and, consequently, increasing the degradation and mineralization of phenol. The stability of the catalysts that revealed better performances in screening experiments was further assessed in consecutive runs, an issue of relevance for actual applications of the CWPO process.

\section{Experimental}

\subsection{Chemicals}

Phenol was obtained from Sigma-Aldrich (99 wt. \%). Hydrogen peroxide solution (30 \%,w/w), p-benzoquinone (99.5 wt. \%) and catechol (98 wt. \%) were purchased from Fluka. Hydroquinone (99 wt. \%), resorcinol (99 wt. \%), titanium(IV) oxysulphate ( 15 wt. \% in dilute sulfuric acid, $99.99 \%$ trace metals basis) and hydrochloric acid (37 wt. \%) were purchased from Sigma-Aldrich. Sulphuric acid (95 wt. \%) and methanol (99.9 wt. \%) were obtained from VWR PROLABO Chemicals. All the solutions were prepared with distilled water.

\subsection{Carbon nanotubes (CNT)}

Six different samples of commercial multi-wall carbon nanotubes (MWCNT) were considered in this work, namely: (i) SA1 / Sigma-Aldrich, ref. 677248 (> $90 \%$ carbon basis, O.D. $x$ I.D. $x$ L: 10-15 nm x 2-6 nm x 0.1-10 $\mu \mathrm{m}$ ); (ii) SA2 / Sigma-Aldrich, ref. 724769 (> $95 \%$ carbon basis, O.D. $x \mathrm{~L}: 6-9 \mathrm{~nm} \times 5 \mu \mathrm{m}$ ); (iii) $\mathrm{NC} / \mathrm{NANOCYL}^{\mathrm{TM}}$, ref. NC3100 (> $95 \%$ carbon basis, average diameter of $9.5 \mathrm{~nm}$ and length of $1.5 \mu \mathrm{m}$ ); (iv) SZ / Shenzhen Nanotech, ref. MWCNT-10 (> $97 \%$ carbon basis, O.D. x L: < $10 \mathrm{~nm}$ x 5-15 $\mu \mathrm{m}$ ); (v) LSZ / Shenzhen Nanotech, long CNTs with ref. L-MWCNT-60100 (> $97 \%$ carbon basis, O.D. x L: 60-100 nm x 5-15 $\mu \mathrm{m}$ ); (vi) SA2-H, resulting from the hydrothermal treatment of SA2 $\left(10 \mathrm{~g} \mathrm{~L}^{-1}\right)$ with concentrated sulfuric acid $\left(18 \mathrm{~mol} \mathrm{~L}^{-1}\right)$ during $3 \mathrm{~h}$ at $423 \mathrm{~K}$. The recovered solids 
were further thoroughly washed with distilled water until the neutrality of the rinsing waters was reached and dried in an oven for $18 \mathrm{~h}$ at $383 \mathrm{~K}$.

\subsection{Characterization techniques}

The catalysts were characterized by different techniques. The textural properties were determined from the $\mathrm{N}_{2}$ adsorption-desorption isotherms at $77 \mathrm{~K}$, obtained in a Quantachrome NOVA 4200e adsorption analyzer. The specific surface area $\left(\mathrm{S}_{\mathrm{BET}}\right)$, pore volume $\left(\mathrm{V}_{\text {total }}\right)$ and micropore volume $\left(\mathrm{V}_{\text {mic }}\right)$ were determined using the $\mathrm{t}$-method and the $\mathrm{BJH}$ pore distribution [19-20].

Temperature programmed desorption (TPD) analysis was performed in a fully automated AMI-300 catalyst characterization instrument (Altamira Instruments), equipped with a quadrupole mass spectrometer (Dymaxion, Ametek). The carbon sample $(0.10 \mathrm{~g})$ was placed in a U-shaped quartz tube inside an electrical furnace and heated at $5 \mathrm{~K} \mathrm{~min}^{-1}$ up to $1073 \mathrm{~K}$ using a constant flow rate of helium $\left(25 \mathrm{~cm}^{3} \mathrm{~min}^{-1}\right)$. The mass signals $\mathrm{m} / \mathrm{z}=28$ and 44 were monitored during the thermal analysis, the corresponding TPD spectra being obtained. $\mathrm{CO}$ and $\mathrm{CO}_{2}$ were calibrated at the end of each analysis with the respective gases [21].

Thermogravimetric analysis (TGA) was performed using a Netzsch STA 409 PC equipment. The sample powders were heated in air (flow $=50 \mathrm{~cm}^{3} \mathrm{~min}^{-1}$ ) from 323 to $1273 \mathrm{~K}$ at $10 \mathrm{~K} \mathrm{~min}^{-1}$.

\subsection{Adsorption and catalytic wet peroxide oxidation experiments}

The experiments were performed in a well-stirred batch glass reactor $(250 \mathrm{~mL})$ immersed in a water bath equipped with a temperature controller. The reactor was loaded with $50 \mathrm{~mL}$ of a $4.5 \mathrm{~g} \mathrm{~L}^{-1}$ phenol solution with the $\mathrm{pH}$ adjusted to 3.5 (with a $1.0 \mathrm{~mol} \mathrm{~L}^{-1} \mathrm{HCl}$ solution) and heated up to the desired temperature. All the experiments were conducted during $24 \mathrm{~h}$ at $353 \mathrm{~K}$, considering an adsorbent/catalyst load of $2.5 \mathrm{~g} \mathrm{~L}^{-1}$. In the CWPO runs, a calculated volume of $\mathrm{H}_{2} \mathrm{O}_{2}$ (30 wt. \%) was injected into the system after catalyst addition, in order to reach the desired 
$\mathrm{H}_{2} \mathrm{O}_{2}$ concentration of $25 \mathrm{~g} \mathrm{~L}^{-1}$ (corresponding approximately to the stoichiometric amount needed to completely mineralize phenol), that moment being considered as $t_{0}=0$ min. Blank experiments, without any catalyst, were also carried out to assess possible non-catalytic oxidation reactions promoted by $\mathrm{H}_{2} \mathrm{O}_{2}$. Adsorption runs (in the absence of $\mathrm{H}_{2} \mathrm{O}_{2}$ ) were also performed with the CNT samples at the same temperature and $\mathrm{pH}$. Selected experiments were performed in triplicate, in order to assess reproducibility and error of the experimental results. It was found that the confidence interval was never superior to $2 \%$, considering $99 \%$ certainty.

\subsection{Analytical methods}

The concentration of phenol and other aromatic compounds were analyzed by high performance liquid chromatography (HPLC) using a Hitachi Elite LaChrom apparatus equipped with a diode array detector (L-2450) and solvent delivery pump (L-2130). The stationary phase consisted in a Purospher Star RP-18 column (250 mm x $4.6 \mathrm{~mm}, 5 \mu \mathrm{m}$ particles) working at room temperature. The method starts with an isocratic method of water (C): methanol (B) (70:30) at a flow rate of $1 \mathrm{~mL} \min ^{-1}$ followed by a linear gradient step to $\mathrm{C}: \mathrm{B}(37: 63)$ in $20 \mathrm{~min}$. Finally, the initial conditions were re-established in a 1 min gradient step and the C:B (70:30) mixture was isocratically eluted for $7 \mathrm{~min}$. The organic compounds were analyzed in a diode array detector at wavelengths from 210 to $290 \mathrm{~nm}$.

The concentration of Fe species leached at the end of the CWPO experiments was determined by atomic absorption, using an atomic absorption spectrometer (Varian Spectra 220). The concentration of $\mathrm{H}_{2} \mathrm{O}_{2}$ was evaluated by a colorimetric method using an UV/VIS spectrophometer (UV Vis Jasco V-560), adapting the procedure described elsewhere [13]. The total organic carbon (TOC) of the samples was analyzed in a Shimadzu TOC-5000A apparatus. 


\section{Results and discussion}

\subsection{Characterization of the CNT samples}

The textural characterization of the CNT samples was carried out by $\mathrm{N}_{2}$ adsorption-desorption isotherms, the results being shown in Table 1. The sample SA2 has the highest specific surface area $\left(\mathrm{S}_{\mathrm{BET}}\right)$ and total pore volume $\left(\mathrm{V}_{\text {total }}\right)$, the $\mathrm{S}_{\mathrm{BET}}$ corresponding to the non-microporous surface area $\left(\mathrm{V}_{\text {micro }}=0 \mathrm{~cm}^{3} \mathrm{~g}^{-1}\right)$. Although lower $\mathrm{S}_{\mathrm{BET}}$ and $\mathrm{V}_{\text {Total }}$ values were obtained, samples SA1, SA2-H and NC reveal quite similar textural properties relatively to SA2. Regarding the commercial MWCNT from Shenzhen Nanotech, SZ and LSZ, these were found to present low specific surface areas and total pore volumes when compared with all the other materials.

\section{TABLE 1}

The surface chemistry characterization was performed by TPD, a popular thermal analysis method for the characterization of oxygen groups on the surface of carbon materials. These oxygen groups decompose with temperature, being evolved as $\mathrm{CO}$ and/or $\mathrm{CO}_{2}$. The release of $\mathrm{CO}$ (between 673 to $1273 \mathrm{~K}$ ) corresponds to the decomposition of carboxylic anhydrides, phenols and quinones, while the release of $\mathrm{CO}_{2}$ (between 473 to $1073 \mathrm{~K}$ ) is attributed to the decomposition of carboxylic acids, lactones and carboxylic anhydrides [22]. The results obtained by TPD analysis of the CNT samples are also shown in Table 1, namely in terms of $\mathrm{CO}$ and $\mathrm{CO}_{2}$ amounts, as well as $\mathrm{CO} / \mathrm{CO}_{2}$ ratio and molecular oxygen percentage. These results show that $\mathrm{NC}$ has the highest amount of oxygen groups released as $\mathrm{CO}$, while the lowest amount was found for SZ. Regarding $\mathrm{CO}_{2}$, LSZ shows the highest value for the release of $\mathrm{CO}_{2}$, while SA1 presents the lowest. The $\mathrm{CO} / \mathrm{CO}_{2}$ ratio is highest for SA1 (5.6), followed by $\mathrm{NC}(5.4)$ and SA2 (4.5), suggesting that these samples present the most pronounced basic character, i.e. $\mathrm{CO} / \mathrm{CO}_{2}$ ratios well above the other samples $(\leq 2.2)$. 


\subsection{Adsorption experiments}

Adsorption experiments were carried out to assess the capacity of the different CNT samples to adsorb phenol, and thus understand the influence of adsorption in the global performance obtained by CWPO (i.e., in experiments in the presence of $\mathrm{H}_{2} \mathrm{O}_{2}$ ). The corresponding time-evolution of phenol concentration obtained in adsorption experiments, performed under the conditions referred in Section 2.4, is shown in Figure 1.

\section{FIGURE 1}

According to Figure 1, a higher adsorption of phenol was observed in $24 \mathrm{~h}$ when the NC sample was employed, followed by $\mathrm{SZ}>\mathrm{SA} 1>\mathrm{SA} 2-\mathrm{H} \approx \mathrm{SA} 2>\mathrm{LSZ}$. For better comparison between the different materials, Table 2 shows detailed data of phenol adsorption removal after $24 \mathrm{~h}$. It is observed that NC presents the highest phenol adsorption removal $\left(198 \mathrm{mg} \mathrm{g}^{-1}\right)$ while LSZ presents the lowest $\left(68 \mathrm{mg} \mathrm{g}^{-1}\right)$, which seems to be related with their respective surface areas (256 and $51 \mathrm{~m}^{2} \mathrm{~g}^{-1}$, respectively, as observed in Table 1). Even so, the adsorption of phenol is not always proportional to $\mathrm{S}_{\mathrm{BET}}$. For example, the specific surface area of $\mathrm{SA} 2-\mathrm{H}$ is higher comparatively to SZ (242 and $41 \mathrm{~m}^{2} \mathrm{~g}^{-1}$, respectively), but SA2-H shows less adsorption than SZ in 24 h. The four possible locations of sites for the adsorption of pollutants on CNT can be classified as: (i) inside channels (inner diameter of the tubes), (ii) interstitial channels (space between different CNT in a bundle), (iii) external groove and (iv) external surface (both related with the outer CNT in a bundle). In addition, different mechanisms may act simultaneously (e.g., electrostatic interactions, hydrophobic interactions, $\pi-\pi$ bonds and hydrogen bonds) and the accessibility of the pollutant to these sites can be affected by functional groups. In this context, the prediction of organic chemical adsorption on CNTs is still a challenging task [23], in particular when the differences in adsorption results are not significant (Figure 1).

\section{TABLE 2}




\section{3. $C W P O$ experiments}

The different CNT samples were tested in CWPO experiments, carried out under the conditions referred in Section 2.4. The results obtained are given in Figure 2. The non-catalytic results (i.e. reaction experiments performed only with $\mathrm{H}_{2} \mathrm{O}_{2}$ ) are also included for comparison.

\section{FIGURE 2}

From the analysis of Figure 2, it is possible to conclude that all catalysts are able to remove more than $80 \%$ of the initial phenol content after $24 \mathrm{~h}$ of reaction (as also shown in Table 2). The best performance was obtained with the catalyst SA1, followed by NC and SA2. These three CNTs show the highest activity, with $100 \%$ phenol removal being obtained. On the other hand, SZ, LSZ and SA2-H show the lowest catalytic activity among all the tested materials. The phenol removals after $24 \mathrm{~h}$ by adsorption and CWPO can be all compared in Table 2.

The highest phenol removal rates (SA1 > NC > SA2, in Figure 2) seems to be well related with the $\mathrm{CO} / \mathrm{CO}_{2}$ ratios of the materials $(5.6>5.4>4.5$, respectively, as observed in Table 1$)$. All these materials also presents quite high BET surface areas $\left(\geq 200 \mathrm{~m}^{2} \mathrm{~g}^{-1}\right)$. However, it is also important to consider that in some cases the results can be explained by the presence of metal particles in the composition of the commercial CNT tested in this work. For instance, according to the manufacturers, SA1 was produced by chemical vapour deposition using iron particles as catalyst (also known as active catalysts in CWPO), whereas SZ and LSZ were synthesized using Co and Mo catalysts (much less active in CWPO). In the particular case of NC, the main metal impurities are $\mathrm{Fe}(0.19 \%)$ and $\mathrm{Co}(0.07 \%)$, as referred elsewhere [24]. In order to assess their possible influence, the Fe species leached into the solution were determined at the end of the CWPO runs. The corresponding results are shown in Figure 3. As observed, the concentration of Fe species in the solution is significantly higher for SA1, namely in the following order: SA1 $\left(26.3 \mathrm{mg} \mathrm{L}^{-1}\right)>>\mathrm{SA} 2\left(2.1 \mathrm{mg} \mathrm{L}^{-1}\right)>\mathrm{NC}\left(1.0 \mathrm{mg} \mathrm{L}^{-1}\right)>\mathrm{SA} 2-\mathrm{H} \approx \mathrm{SZ}\left(0.6 \mathrm{mg} \mathrm{L}^{-1}\right)>\mathrm{LSZ}$ $\left(0.1 \mathrm{mg} \mathrm{L}^{-1}\right)$. 
Fe species are known to catalyze $\mathrm{H}_{2} \mathrm{O}_{2}$ decomposition into reactive $\mathrm{HO}^{\bullet}$ radicals in acid solutions [25-28]. In this mechanism, regarding the radicals generated, $\mathrm{Fe}^{2+}$ and $\mathrm{H}_{2} \mathrm{O}_{2}$ lead to the formation of $\mathrm{HO}^{\cdot}$ and $\mathrm{Fe}^{3+}$, and then $\mathrm{Fe}^{3+}$ is converted into $\mathrm{Fe}^{2+}$ through the formation of hydroperoxyl radicals $\left(\mathrm{HO}_{2}^{*}\right)$. For the CNT tested in this work, these reactions can occur both at the catalyst surface and in solution, since the concentration of Fe species leached into the solution $(\mathrm{SA} 1>\mathrm{SA} 2>\mathrm{NC}$ ) does not correlate with the extents observed in Figure 2 for the degradation of phenol $(\mathrm{SA} 1>\mathrm{NC}>\mathrm{SA} 2)$.

\section{FIGURE 3}

Figure 3 also shows the total organic carbon (TOC) conversions obtained at the end of the CWPO runs. As observed, the level of mineralization increases with the phenol removal. SA1 presents the highest TOC conversion $(77 \%)$, followed by NC $(69 \%)>\mathrm{SA} 2(67 \%)>\mathrm{SA} 2-\mathrm{H}$ $(58 \%)>\operatorname{LSZ}(46 \%)>\mathrm{SZ}(45 \%)$. As in the case of phenol conversions, TOC removals does not correlate directly to Fe species leached into the solution.

Although phenol is completely removed with SA1, NC and SA2, a fraction of the initial TOC remains in the final aqueous solution. This suggests the formation of reaction intermediates, such as aromatic compounds (like hydroquinone, resorcinol, $p$-benzoquinone and catechol) and their oxidation by-products. Possible explanations for the incomplete TOC abatement may be (i) inhibition of effective $\mathrm{H}_{2} \mathrm{O}_{2}$ decomposition to $\mathrm{HO}^{\bullet}$ radicals due to the presence of organic compounds on the catalyst surface (i.e. a competitive process between $\mathrm{H}_{2} \mathrm{O}_{2}$ and the organic molecules for the active sites at the catalyst surface) [18]; (ii) thermal decomposition of $\mathrm{H}_{2} \mathrm{O}_{2}$ during reaction, as described by Eq. (1) (although limited in the presence of a catalyst, it depends on the carbon texture and surface chemistry); and (iii) several other pathways avoiding effective usage of $\mathrm{HO}^{\bullet}$ radicals for degradation of phenol oxidation intermediates [13], such as those given in Eqs. (2) to (5). As described in these equations, the free radicals may react with each other or may also react with $\mathrm{H}_{2} \mathrm{O}_{2}$. Generally speaking, a high concentration of $\mathrm{H}_{2} \mathrm{O}_{2}$ does not necessarily leads to higher TOC removal in CWPO, and the use of an excess of oxidant is 
often useless in that regard [29-33]. In fact, as observed in Figure 3, the $\mathrm{H}_{2} \mathrm{O}_{2}$ conversions are quite high regardless the catalyst tested and the respective TOC abatement, suggesting the occurrence of the parasitic reactions described in Eq. (2) to (5).

$$
\begin{aligned}
& \mathrm{HO}^{\bullet}+\mathrm{H}_{2} \mathrm{O}_{2} \rightarrow \mathrm{HO}_{2}^{\bullet}+\mathrm{H}_{2} \mathrm{O} \\
& \mathrm{HO}^{\bullet}+\mathrm{HO}_{2}^{\bullet} \rightarrow \mathrm{O}_{2}+\mathrm{H}_{2} \mathrm{O} \\
& \mathrm{HO}^{\bullet}+\mathrm{HO}^{\bullet} \rightarrow \mathrm{H}_{2} \mathrm{O}_{2} \\
& \mathrm{HO}_{2}^{\bullet}+\mathrm{HO}_{2}^{\bullet} \rightarrow \mathrm{O}_{2}+\mathrm{H}_{2} \mathrm{O}_{2}
\end{aligned}
$$

Phenol can be degraded by $\mathrm{HO}^{\circ}$ radicals, typically through an electrophilic addition to the aromatic ring [34]. Due to the influence of the phenolic - $\mathrm{OH}$ group, this addition will occur mainly in selective ortho and/or para positions, leading to the formation of catechol and hydroquinone, respectively [34]. Nevertheless, the formation of resorcinol is also expected due to residual electrophilic addition in selective meta position $[18,35]$. Furthermore, hydroquinone is known to be very easily oxidized into $p$-benzoquinone [36]. In order to further explore the reaction mechanism, the occurrence of some possible aromatic intermediates resulting from phenol CWPO was investigated as described in Section 2.5. SA2 and NC were selected for this study, since higher TOC removals are obtained when they are employed in the CWPO process (SA1 was discarded for further studies due to the high leaching observed). As expected, hydroquinone, resorcinol, p-benzoquinone and catechol were detected when using both catalysts, the corresponding evolution being shown in Figures $4 \mathrm{a}$ and $4 \mathrm{~b}$, for SA2 and NC catalysts, respectively. As it can be seen, the maximum concentrations of the intermediates are generally obtained after ca. $1.5 \mathrm{~h}$ of reaction, then decreasing significantly until residual concentrations being reached at the end of the CWPO experiments performed with the highly polluted phenol solution $\left(4.5 \mathrm{~g} \mathrm{~L}^{-1}\right.$ ) during $24 \mathrm{~h}$. This suggests that other by-products (such as low weight carboxylic acids) should also be present in solution at the end of the CWPO runs, resulting from the aromatic ring cleavage [18]. 


\section{FIGURE 4}

The concentration of the aromatic intermediate compounds (Figure 4) increases/decreases according to the reaction described by Eq. (6), and among them the highest concentration was observed for catechol (followed by $p$-benzoquinone $>$ hydroquinone > resorcinol). The concentrations of $p$-benzoquinone and hydroquinone (formed by para-hydroxylation) were ca. 20-40 \% to that of catechol. Resorcinol (formed by meta-hydroxylation) was present only in trace amounts in the catalytic run carried out with SA2, while a concentration of approximately $20 \%$ to that of catechol was detected in the run with NC.

$$
\mathrm{C}_{6} \mathrm{H}_{5} \mathrm{OH}+14 \mathrm{H}_{2} \mathrm{O}_{2} \rightarrow \text { Intermediates } \rightarrow 6 \mathrm{CO}_{2}+17 \mathrm{H}_{2} \mathrm{O}
$$

Summarizing, a graphical representation of the mechanism for phenol CWPO is given in Figure 5, which has been widely described in literature for phenol oxidation by AOPs [37].

\section{FIGURE 5}

\subsection{Catalyst stability and reusability studies}

Catalysts SA2 and NC were recovered by filtration after the CWPO experiments in order to assess their stability and reusability characteristics. The materials were washed, dried at room temperature for $12 \mathrm{~h}$ and then at $393 \mathrm{~K}$ for $3 \mathrm{~h}$. Afterwards, the catalysts were reused with fresh phenol solutions. Figures $6 \mathrm{a}$ and $6 \mathrm{~b}$ show the results obtained with SA2 and NC, respectively, including phenol and TOC conversions, leaching of Fe species and the $\mathrm{X}_{\mathrm{TOC}} / \mathrm{X}_{\mathrm{H}_{2} \mathrm{O}_{2}}$ ratio after $24 \mathrm{~h}$, a parameter that defines the efficiency of $\mathrm{H}_{2} \mathrm{O}_{2}$ consumption in the CWPO process. It is observed, for both catalysts, that the degradation of phenol and TOC decreases slightly with the reusing cycles. Notwithstanding, the conversions still remain high. Regarding the concentration of Fe species leached into solution, a significant decrease is observed from the first to the second run in the case of SA2. However, this decrease is not followed by a loss of efficiency of the catalyst. This evidence may indicate that although Fe species are being transferred to the solution with a corresponding possible contribution of homogeneous catalysis in the generation 
of $\mathrm{HO}^{\bullet}$ radicals, and subsequent phenol degradation, the catalyst unequivocally possesses intrinsic heterogeneous activity for the CWPO process. Relatively to NC, the decrease of phenol conversion from the first to the second run is slightly higher when compared to that of SA2. Nevertheless, despite the negligible Fe leached to the solution in the third run $\left(<0.1 \mathrm{mg} \mathrm{L}^{-1}\right)$, TOC removal is barely affected during its successive reuse.

\section{FIGURE 6}

The apparent slight loss of activity observed with the SA2 and NC catalysts may be explained by adsorption of the pollutant at the catalyst surface in the first run or even by deposition of some other species, such as reaction by-products, on the catalyst surface [18]. In order to explore this hypothesis, TPD analysis was performed for the original SA2 (Figures 7a and $7 \mathrm{~b}$ ) and $\mathrm{NC}$ (Figures $7 \mathrm{c}$ and $7 \mathrm{~d}$ ) materials as well as for the respective samples recovered after the first and the third reaction runs, in terms of $\mathrm{CO}$ (Figures 7a and 7c) and $\mathrm{CO}_{2}$ (Figures $7 \mathrm{~b}$ and $7 \mathrm{~d}$ ) evolution. The most important finding is that the amount of carboxylic acids (decomposing at the lower temperatures as $\mathrm{CO}_{2}[22]$ ) increases after the CWPO runs, while the other groups evolved as $\mathrm{CO}_{2}$ or even $\mathrm{CO}$ are not so significantly affected. Thus the $\mathrm{CO} / \mathrm{CO}_{2}$ ratio decreases upon catalyst reuse (namely from 4.5 to 0.5 in the case of SA2 and from 5.4 to 0.9 in NC), indicating that carboxylic acids are adsorbed on the catalyst surface or/and that the catalyst is oxidized by $\mathrm{H}_{2} \mathrm{O}_{2}$ during the CWPO reactions generating mainly carboxylic acid groups. This effect is particularly remarkable during the first reaction run. As a consequence, the adsorbed organic compounds can lead to the blockage of the active sites available for $\mathrm{H}_{2} \mathrm{O}_{2}$ decomposition, while at the same time the introduction of oxygen electron-withdrawing groups can diminish the electron density at the carbon surface, also reducing the catalyst activity. Therefore, these changes can be responsible by the slight decrease in the catalysts activity in the successive reutilization experiments (Figure 6).

\section{FIGURE 7}


In order to get more insights, TGA under air atmosphere was performed for the original SA2 catalyst and for the samples recovered after the first and the third reaction runs (Figure 8). The original catalyst shows quite high stability since its gasification starts at high temperatures (773 K). However, the samples after the first and the third runs started to lose weight around $473 \mathrm{~K}$, in agreement with TPD analysis (Figure $7 \mathrm{~b}$ ). Therefore, this can be attributed to oxidation of the adsorbed by-products or to the decomposition of surface oxygen groups generated during reaction, thus suggesting that these phenomena are the possible cause for the slight loss of activity observed with the catalysts upon reuse.

Regarding the $\mathrm{X}_{\mathrm{TOC}} / \mathrm{X}_{\mathrm{H}_{2} \mathrm{O}_{2}}$ ratios reported in Figure 6, it is observed that this parameter presents similar values for the two catalysts in the successive reuses (ranging between 0.72 and 0.64), suggesting that a large percentage of the oxidizing agent is effectively used in the mineralization of phenol. Thus, with the results obtained in this work, it is concluded that SA2 and NC are catalysts with moderate stability for long-term reaction runs, able to promote the CWPO of highly concentrated phenol solutions with a good efficiency of $\mathrm{H}_{2} \mathrm{O}_{2}$ consumption, making these commercial materials suitable for industrial applications on wastewater treatment.

\section{FIGURE 8}

\section{Conclusions}

Commercial multi-wall carbon nanotubes with different properties were tested for the treatment of highly concentrated phenol solutions by catalytic wet peroxide oxidation. Considering phenol and total organic carbon removals, as well as the extent of Fe species leached into solution, the catalysts with best performance were SA2 (obtained from Sigma-Aldrich, ref.72476) and NC (obtained from NANOCYL, ref. NANOCYL ${ }^{\mathrm{TM}}$ NC3100). Aromatic reaction by-products like catechol, $p$-benzoquinone, hydroquinone and resorcinol were the compounds identified in higher concentrations. Based on reutilization experiments 
performed with SA2 and NC, it can be concluded that these materials are fairly stable, with a slight loss of activity being observed in three consecutive runs. The activity decrease of the catalysts was more likely ascribed to adsorbed organic compounds, such as low molecular weight carboxylic acids, which can block the sites for $\mathrm{H}_{2} \mathrm{O}_{2}$ decomposition, but other possible explanation is the generation of carboxylic acid groups, which can reduce the electron density on the carbon surface of the carbon nanotubes.

\section{Acknowledgments}

Work supported by projects PTDC/AAC-AMB/110088/2009, PEst-C/EQB/LA0020/2013, NORTE-07-0162-FEDER-000050 and NORTE-07-0124-FEDER-0000015, co-financed by FEDER through COMPETE, QREN and ON2, and by FCT - Fundação para a Ciência e a Tecnologia. RSR acknowledges the FCT individual PhD grant SFRH/BD/94177/2013.

\section{References}

[1] S. Azabou, W. Najjar, M. Bouaziz, A. Ghorbel, S. Sayadi, Journal of Hazardous Materials 183 (2010) 62-69.

[2] G. Busca, S. Berardinelli, C. Resini, L. Arrighi, Journal of Hazardous Materials 160 (2008) 265-288.

[3] N.S. Inchaurrondo, P. Massa, R. Fenoglio, J. Font, P. Haure, Chemical Engineering Journal 198-199 (2012) 426-434.

[4] J.A. Zazo, J.A. Casas, A.F. Mohedano, J.J. Rodríguez, Applied Catalysis B: Environmental 65 (2006) 261-268.

[5] A.B. Ayusheev, O.P. Taran, I.A. Seryak, O.Y. Podyacheva, C. Descorme, M. Besson, L.S. Kibis, A.I. Boronin, A.I. Romanenko, Z.R. Ismagilov, V. Parmon, Applied Catalysis B: Environmental 146 (2014) 177-185. 
[6] R. Andreozzi, V. Caprio, A. Insola, R. Marotta, Catalysis Today 53 (1999) 51-59.

[7] L.F. Liotta, M. Gruttadauria, G. Di Carlo, G. Perrini, V. Librando, Journal of Hazardous Materials 162 (2009) 588-606.

[8] J.A. Zazo, A.F. Fraile, A. Rey, A. Bahamonde, J.A. Casas, J.J. Rodriguez, Catalysis Today 143 (2009) 341-346.

[9] F. Duarte, F.J. Maldonado-Hódar, L.M. Madeira, Applied Catalysis B: Environmental 103 (2011) 109-115.

[10] J.A. Zazo, J. Bedia, C.M. Fierro, G. Pliego, J.A. Casas, J.J. Rodriguez, Catalysis Today 187 (2012) 115-121.

[11] J.H. Ramirez, F.J. Maldonado-Hódar, A.F. Pérez-Cadenas, C. Moreno-Castilla, C.A. Costa, L.M. Madeira, Applied Catalysis B: Environmental 75 (2007) 312-323.

[12] A. Dhaouadi, N. Adhoum, Applied Catalysis B: Environmental 97 (2010) 227-235.

[13] R.S. Ribeiro, A.M.T. Silva, J.L. Figueiredo, J.L. Faria, H.T. Gomes, Applied Catalysis B: Environmental 140-141 (2013) 356-362.

[14] H.T. Gomes, S.M. Miranda, M.J. Sampaio, A.M.T. Silva, J.L. Faria, Catalysis Today $151(2010)$ 153-158.

[15] H.T. Gomes, S.M. Miranda, M.J. Sampaio, J.L. Figueiredo, A.M.T. Silva, J.L. Faria, Applied Catalysis B: Environmental 106 (2011) 390-397.

[16] C.M. Domínguez, P. Ocón, A. Quintanilla, J.A. Casas, J.J. Rodriguez, Applied Catalysis B: Environmental 144 (2014) 599-606.

[17] M. Kumar, Y. Ando, Journal of Nanoscience and Nanotechnology 10 (2010) 3739-3758.

[18] C.M. Domínguez, P. Ocón, A. Quintanilla, J.A. Casas, J.J. Rodriguez, Applied Catalysis B: Environmental 140-141 (2013) 663-670.

[19] K.S.W. Sing, D.H. Everett, R.A.W. Haul, L. Moscou, R.A. Pierotti, J. Rouquerol, T. Siemieniewska, Handbook of Heterogeneous Catalysis, Wiley-VCH Verlag GmbH \& Co. KGaA, 2008. 
[20] M. Omid, in: J.C. Moreno-Pirajan (Ed.), Thermodynamics - Interaction studies - Solids, liquids and gases, InTech, 2011.

[21] J.L. Figueiredo, M.F.R. Pereira, M.M.A. Freitas, J.J.M. Órfão, Carbon 37 (1999) 13791389.

[22] J.L. Figueiredo, M.F.R. Pereira, Catalysis Today 150 (2010) 2-7.

[23] C. Qiao, Y. Xing, Q. Jiao, Water Science \& Technology 68 (2013) 1679-1687.

[24] J.-P. Tessonnier, D. Rosenthal, T.W. Hansen, C. Hess, M.E. Schuster, R. Blume, F. Girgsdies, N. Pfänder, O. Timpe, D.S. Su, R. Schlögl, Carbon 47 (2009) 1779-1798.

[25] J.M. Peralta-Hernández, Y. Meas-Vong, F.J. Rodríguez, T.W. Chapman, M.I. Maldonado, L.A. Godínez, Dyes and Pigments 76 (2008) 656-662.

[26] S. Esplugas, J. Giménez, S. Contreras, E. Pascual, M. Rodríguez, Water Research 36 (2002) 1034-1042.

[27] K. Rusevova, R. Köferstein, M. Rosell, H.H. Richnow, F.-D. Kopinke, A. Georgi, Chemical Engineering Journal 239 (2014) 322-331.

[28] W.P. Kwan, B.M. Voelker, Environmental Science \& Technology 37 (2003) 1150-1158.

[29] X. Zhong, J. Barbier Jr, D. Duprez, H. Zhang, S. Royer, Applied Catalysis B: Environmental 121-122 (2012) 123-134.

[30] C. Di Luca, F. Ivorra, P. Massa, R. Fenoglio, Industrial and Engineering Chemistry Research 51 (2012) 8979-8984.

[31] L. Hou, Q. Zhang, F. Jérôme, D. Duprez, H. Zhang, S. Royer, Applied Catalysis B: Environmental 144 (2014) 739-749.

[32] S. Ghafoori, M. Mehrvar, P.K. Chan, Industrial \& Engineering Chemistry Research 51 (2012) 14980-14993.

[33] R. Alnaizy, A. Akgerman, Advances in Environmental Research 4 (2000) 233-244.

[34] F.A. Carey, R.J. Sundberg, Advanced Organic Chemistry, 3rd ed., Plenum Press, New York, 1990. 
[35] J. Morales-Roque, M. Carrillo-Cárdenas, N. Jayanthi, J. Cruz, T. Pandiyan, Journal of Molecular Structure: THEOCHEM 910 (2009) 74-79.

[36] M.A. Oturan, J. Peiroten, P. Chartrin, A.J. Acher, Environmental Science \& Technology 34 (2000) 3474-3479.

[37] A. Santos, P. Yustos, A. Quintanilla, S. Rodríguez, F. García-Ochoa, Applied Catalysis B: Environmental 39 (2002) 97-113. 


\section{TABLES}

Table1. Textural properties and surface chemistry of the different carbon nanotubes: specific surface area $\left(\mathrm{S}_{\mathrm{BET}}, \pm 10 \mathrm{~m}^{2} \mathrm{~g}^{-1}\right)$, total pore volume $\left(\mathrm{V}_{\text {Total }}, \pm 0.01 \mathrm{~cm}^{3} \mathrm{~g}^{-1}\right)$ and concentration of oxygen containing functionalities $\left( \pm 20 \mu \mathrm{mol} \mathrm{g}^{-1}\right.$ ) released as $\mathrm{CO}$ and $\mathrm{CO}_{2}$ during TPD analysis.

\begin{tabular}{|c|c|c|c|c|c|c|}
\hline Sample & $\begin{array}{c}\mathrm{S}_{\mathrm{BET}} \\
\left(\mathrm{m}^{2} \mathrm{~g}^{-1}\right)\end{array}$ & $\begin{array}{c}\mathrm{V}_{\text {total }} \\
\left(\mathrm{cm}^{3} \mathrm{~g}^{-1}\right)\end{array}$ & $\begin{array}{c}\mathrm{CO} \\
\left.(\mu \mathrm{mol} \mathrm{g})^{-1}\right)\end{array}$ & $\begin{array}{c}\mathrm{CO}_{2} \\
\left(\mu \mathrm{mol} \mathrm{g}{ }^{-1}\right)\end{array}$ & $\mathrm{CO} / \mathrm{CO}_{2}$ & $\begin{array}{l}\mathrm{O}_{2} \\
(\%)\end{array}$ \\
\hline SA1 & 200 & 1.5 & 594 & 107 & 5.6 & 1.3 \\
\hline SA2 & 291 & 3.2 & 785 & 174 & 4.5 & 1.8 \\
\hline SA2-H & 242 & 2.9 & 750 & 344 & 2.2 & 2.3 \\
\hline $\mathrm{NC}$ & 256 & 2.8 & 1003 & 186 & 5.4 & 2.2 \\
\hline SZ & 41 & 0.17 & 390 & 238 & 1.6 & 1.4 \\
\hline LSZ & 51 & 0.17 & 569 & 481 & 1.2 & 2.4 \\
\hline
\end{tabular}


Table 2. Phenol removal after $24 \mathrm{~h}( \pm 1 \%)$ obtained by pure adsorption (Ads.) and CWPO under intensified conditions $\left([\mathrm{phenol}]=4.5 \mathrm{~g} \mathrm{~L}^{-1}\right.$, catalyst load $=2.5 \mathrm{~g} \mathrm{~L}^{-1}, \mathrm{~T}=353 \mathrm{~K}$ and $\mathrm{pH}=$ 3.5) when using different carbon nanotubes.

\begin{tabular}{ccccc}
\hline \multicolumn{5}{c}{ Phenol removal } \\
\hline Material & Ads. & CWPO & Ads. & CWPO \\
& $(\%)$ & $(\%)$ & $\left(\mathrm{mg} \mathrm{g}^{-1}\right)$ & $\left(\mathrm{mg} \mathrm{g}^{-1}\right)$ \\
\hline SA1 & 7.9 & 100 & 142 & 1800 \\
SA2 & 4.7 & 100 & 85 & 1800 \\
SA2-H & 5.0 & 89 & 90 & 1602 \\
NC & 11 & 100 & 198 & 1800 \\
SZ & 9.0 & 83 & 162 & 1494 \\
LSZ & 3.8 & 84 & 68 & 1512 \\
\hline
\end{tabular}




\section{FIGURE CAPTIONS}

Figure 1. Normalized phenol concentration decay curves obtained in phenol adsorption runs performed with the different carbon nanotubes during 24 h. Adsorption conditions: [phenol] $=4.5 \mathrm{~g} \mathrm{~L}^{-1}$, adsorbent load $=2.5 \mathrm{~g} \mathrm{~L}^{-1}, \mathrm{~T}=353 \mathrm{~K}$ and $\mathrm{pH}=3.5$.

Figure 2. Normalized phenol concentration decay curves obtained in phenol CWPO runs performed with the different carbon nanotubes during 24 h. Reaction conditions: [phenol] $=4.5 \mathrm{~g} \mathrm{~L}^{-1}$, catalyst load $=2.5 \mathrm{~g} \mathrm{~L}^{-1}, \mathrm{~T}=353 \mathrm{~K}, \mathrm{pH}=3.5$ and $\left[\mathrm{H}_{2} \mathrm{O}_{2}\right]=25 \mathrm{~g} \mathrm{~L}^{-1}$. The results obtained in the non-catalytic experiments are also shown for comparison.

Figure 3. Phenol, TOC and $\mathrm{H}_{2} \mathrm{O}_{2}$ conversion (bars and squares/left axis) and concentration of Fe species leached (circles/right axis), after $24 \mathrm{~h}$, in CWPO runs performed with the different carbon nanotubes.

Figure 4. Concentration of aromatic intermediates detected in the CWPO of phenol as a function of time when using the SA2 (a) and NC (b) catalysts.

Figure 5. Schematic representation for phenol conversion pathway in CWPO.

Figure 6. Phenol and TOC removal (bars/left axis), concentration of iron leached and $\mathrm{X}_{\mathrm{TOC}} / \mathrm{X}_{\mathrm{H}_{2} \mathrm{O}_{2}}$ (squares/right axis), after $24 \mathrm{~h}$, in the series of three consecutive CWPO runs performed with the SA2 (a) and NC (b) catalysts.

Figure 7. TPD spectra before CWPO and after the $1^{\text {st }}$ and the $3^{\text {rd }}$ uses of the catalyst SA2 $(a, b)$ and of the catalyst $\mathrm{NC}(\mathrm{c}, \mathrm{d})$ in terms of $\mathrm{CO}(\mathrm{a}, \mathrm{c})$ and $\mathrm{CO}_{2}(\mathrm{~b}, \mathrm{~d})$ evolution.

Figure 8. TGA of the catalyst SA2 before CWPO and after the $1^{\text {st }}$ and the $3^{\text {rd }}$ uses, obtained under air atmosphere with a $10 \mathrm{~K} \mathrm{~min}^{-1}$ heating rate. 


\section{FIGURE 1}

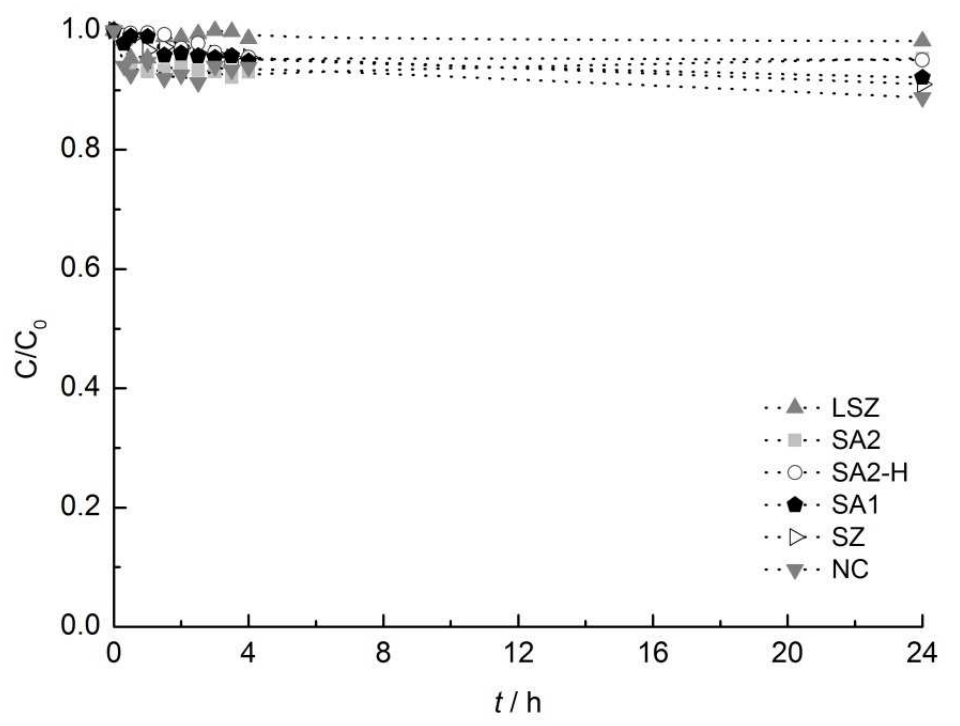




\section{FIGURE 2}

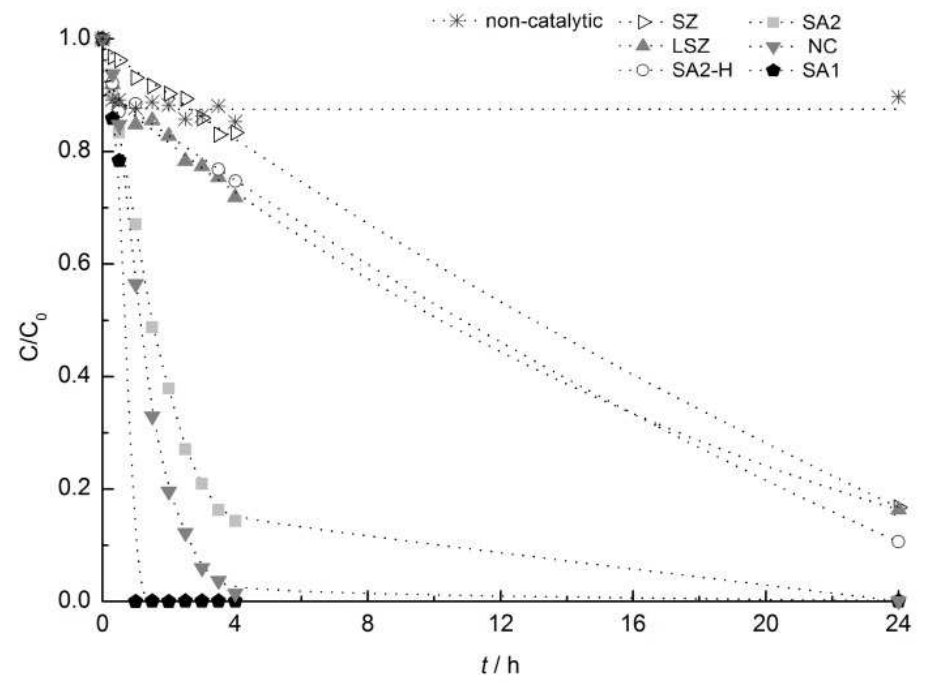


FIGURE 3

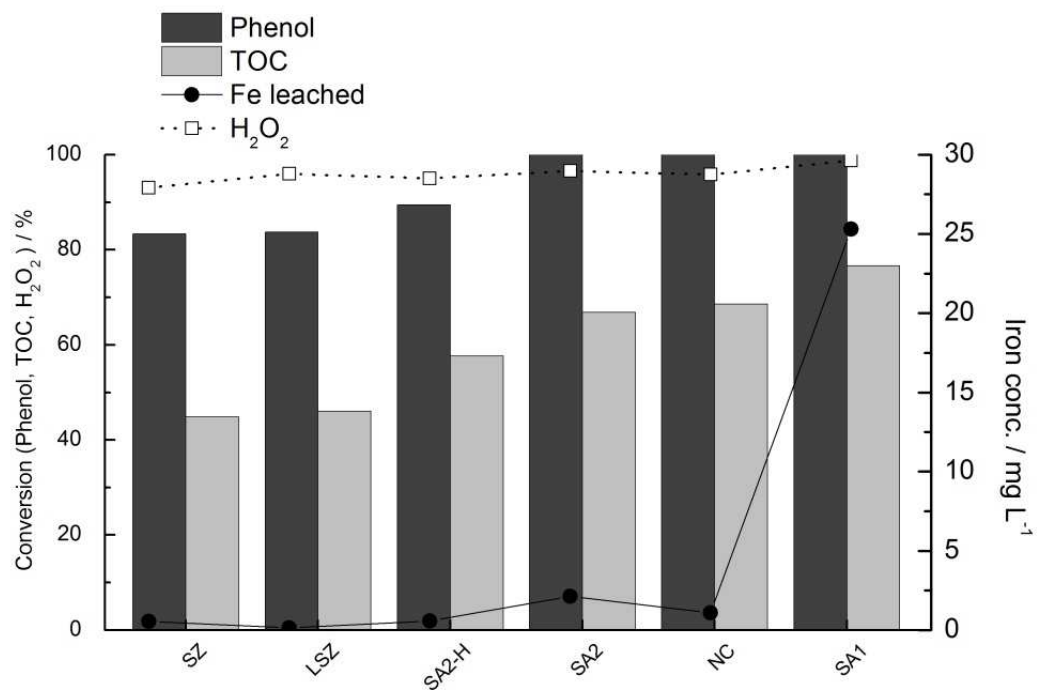




\section{FIGURE 4}
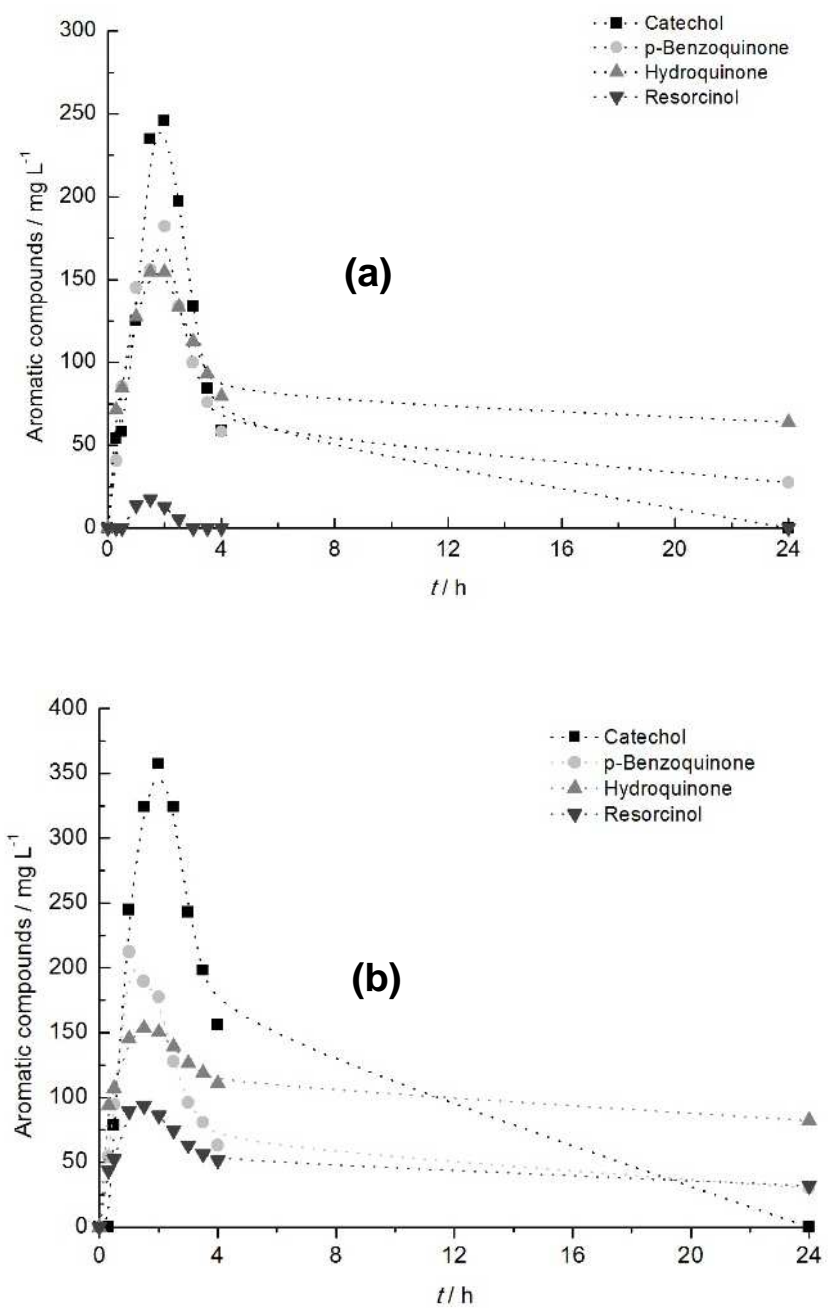


\section{FIGURE 5}

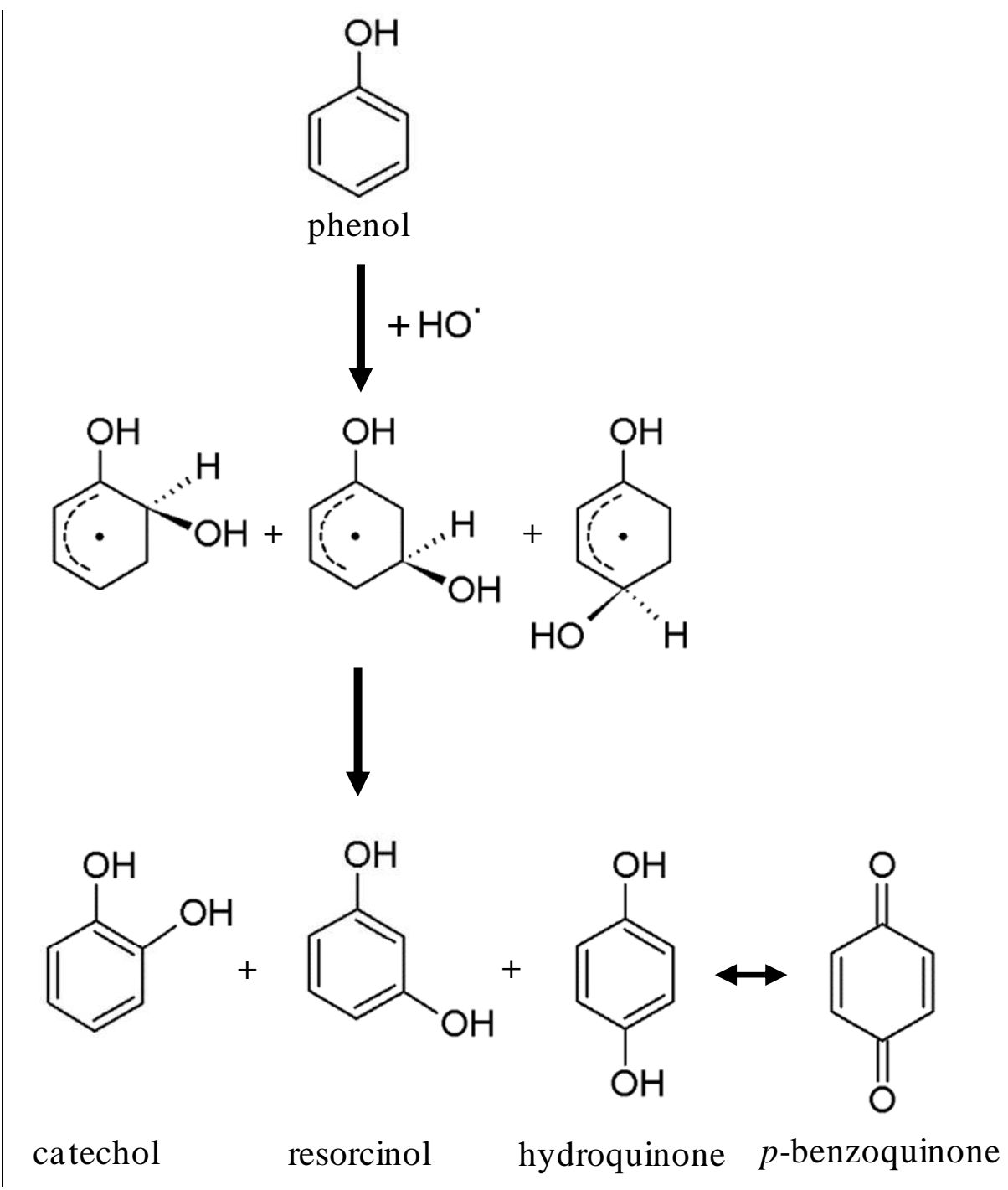


FIGURE 6

(a) $\underset{\substack{\text { Phenol } \\-\mathrm{Fel}}}{\mathrm{P} \text { lead }}$

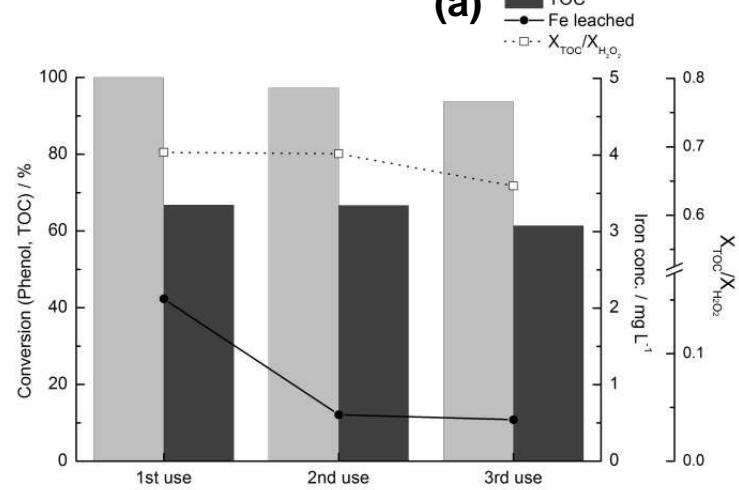

(b) $\square_{\text {Toc }}^{\text {Phen }}$

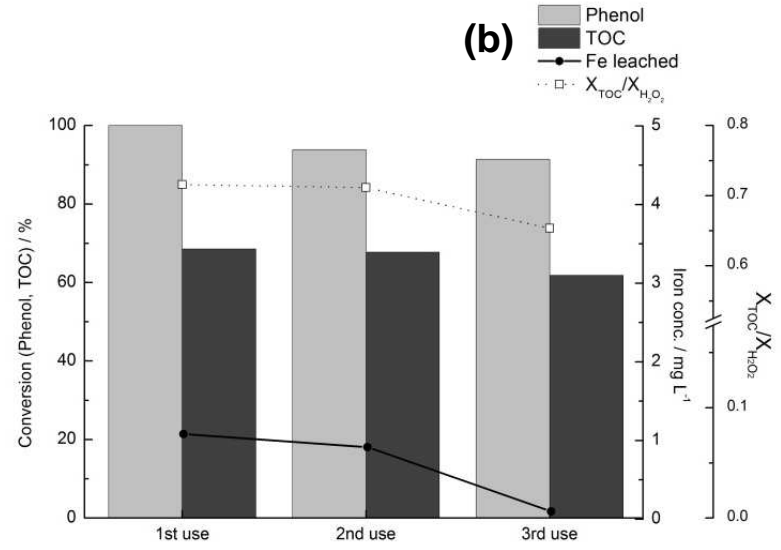




\section{FIGURE 7}
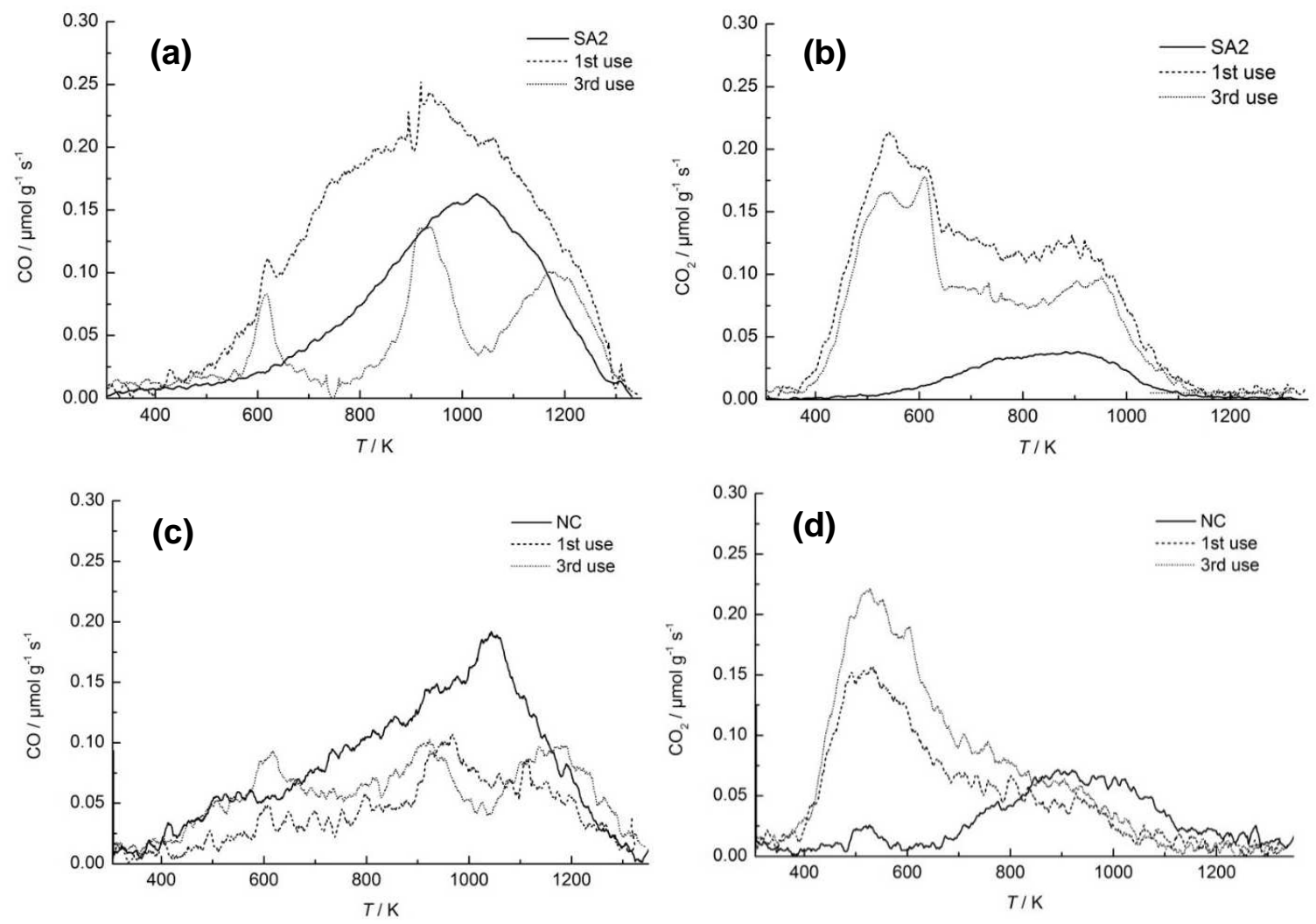


\section{FIGURE 8}

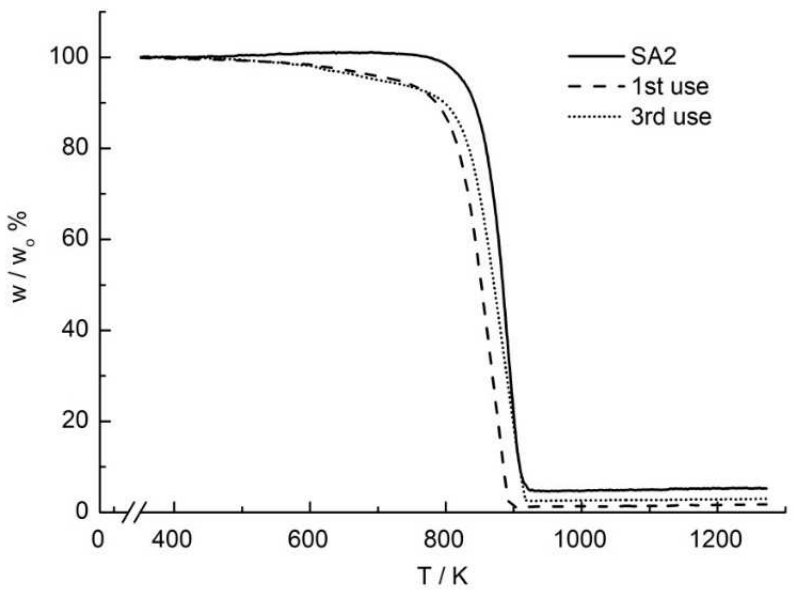




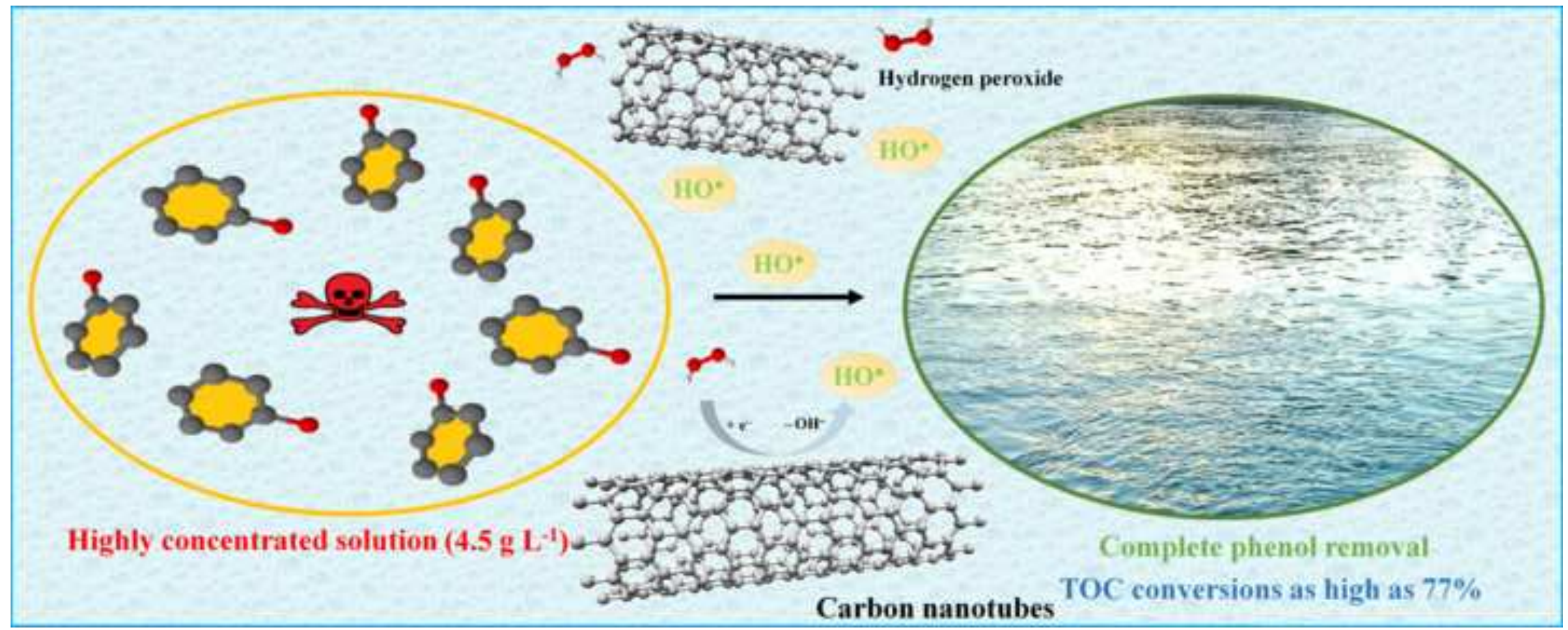

